\title{
Effect of Clinical and Treatment Factors on Survival Outcomes of Triple Negative Breast Cancer Patients
}

This article was published in the following Dove Press journal:

Breast Cancer: Targets and Therapy

\author{
Shelly Wen ${ }^{1,2}$ \\ Lucy Manuel ${ }^{1,2}$ \\ Moira Doolan ${ }^{1,2}$ \\ Justin Westhuyzen (D) \\ Thomas P Shakespeare ${ }^{1,2}$ \\ Noel J Aherne ${ }^{1,2}$ \\ 'Department of Radiation Oncology, Mid \\ North Coast Cancer Institute, Coffs \\ Harbour, New South Wales, Australia; \\ ${ }^{2}$ University of New South Wales, Sydney, \\ New South Wales, Australia
}

\begin{abstract}
Purpose: Triple negative breast cancer (TNBC) accounts for approximately $15 \%$ of breast cancer cases and is associated with a poor prognosis. In this retrospective study of patients undergoing radiation therapy as part of their treatment, disease-free survival (DFS) and overall survival (OS) of TNBC patients were examined in relation to clinical and treatmentrelated factors.
\end{abstract}

Patients and Methods: The electronic records of 214 consecutive TNBC patients treated with surgery followed by radiotherapy at the Mid North Coast Cancer Institute between 2006 and 2016 were reviewed. Overall survival and DFS times were analyzed using the KaplanMeier method; multivariate Cox proportional hazard regression modelling was used to assess the significance of prognostic factors.

Results: The majority of tumors were T1 (51.9\%), followed by T2 (39.2\%) and T3 (6.1\%). For the whole group, mean DFS was 106.4 (SD 48.7) months; OS 109.4 (SD 52.1) months. Radiotherapy technique, fractionation protocol and laterality were not significant factors for DFS or OS $(p>0.05)$. However, compared to breast conservation, mastectomy was associated with poorer DFS (mean 114.2 vs 65.2 months; $p<0.0001$ ) and poorer OS (mean 115.5 vs 80.5 months; $p=0.0015)$. The mastectomy group had fewer patients with tumor size $\mathrm{T} 1(p=0.001)$ and higher proportions of T3 $(p=0.001)$ and T4 $(p=0.02)$. On multivariate analysis, tumor size T3/T4 and nodal status N2/N3 were significant factors for reduced DFS ( $p=0.023$ and $p=0.0003$ respectively). Tumor size T3/T4 was the only significant prognostic factor for reduced OS $(p=0.019)$.

Conclusion: Advanced disease exhibited by tumor size $>5 \mathrm{~cm}$ and positive nodal status is associated with poorer DFS in TNBC patients. Radiotherapy technique or fractionation protocol were not associated with differences in DFS or OS in our patient cohort.

Keywords: dose fractionation, mastectomy, radiotherapy, survival analysis, triple negative breast neoplasms

\section{Plain Language Summary}

Triple negative breast cancer (TNBC) is an uncommon form of breast cancer that is characterized by a particularly poor prognosis.

In this study we were interested in the clinical and treatment-related factors which influence these patients' survival. As all 214 patients in our study received radiation therapy, we examined the type of radiation technique used (conventional radiotherapy vs intensity modulated radiotherapy [IMRT]), the number of radiation fractions delivered (conventionally fractionated delivery vs hypofractionated delivery), chemotherapy usage and the type of surgery used (mastectomy vs breast-conserving surgery).

On average, the time between diagnosis and re-appearance of the tumor was 106 months. Overall survival averaged 109 months. Using appropriate (Cox proportional hazard modelling),
Correspondence: Noel J Aherne Department of Radiation Oncology, Mid North Coast Cancer Institute, Coffs Harbour NSW 2450, Australia

Tel +6I-2-6656-7000

Fax +6I-2-6656-5330

Email noel.aherne@health.nsw.gov.au
Breast Cancer: Targets and Therapy 2020:12 27-35 
we found that chemotherapy usage, radiotherapy technique, fractionation protocol and laterality (left vs right breast) were not significant factors for determining disease-free survival nor overall survival $(p>0.05)$. However, larger tumors $(>5 \mathrm{~cm})$ and nodal involvement were associated with poorer disease-free survival; larger tumors $(>5 \mathrm{~cm})$ were associated with poorer overall survival. For patients with TNBC, as in other types of breast cancer, early detection provides the best chance of effective treatment.

\section{Introduction}

Breast cancer is the most commonly diagnosed cancer in females in Australia with an estimated 17,730 new cases in $2017 .{ }^{1}$ Breast cancer is the second most common cause of death from cancer in women, with an estimated 3114 deaths expected in 2017. Breast cancer is a heterogenous disease, with molecular subtyping based on the expression of several hormone receptors: estrogen receptor (ER), progesterone receptor (PR), and human epidermal growth factor receptor 2 (HER2). ${ }^{2}$ Clinical and pathological features vary between the subgroups, as do survival outcomes. Triple negative breast cancer (TNBC) lacks all three receptors and accounts for approximately $15 \%$ of breast cancer cases. ${ }^{3-5}$ Patients with TNBC are often younger and there is considerable overlap with BRCA-1 related breast cancer mutation. ${ }^{6,7}$ Cancers are often more aggressive, with higher rates of local recurrence and poor survival. $^{5,8}$

The choice of therapy and surgical approach largely depends on tumor characteristics. ${ }^{9}$ Therapeutic options for TNBC are limited to non-targeted therapies due to a lack of an identified molecular target. ${ }^{10}$ Breast conservation surgery is an option for early breast cancer followed by adjuvant radiation therapy; recent reviews suggest that, after adjusting for age at diagnosis, stage, histology and grade, survival was equal or better after breast conservation surgery than mastectomy. ${ }^{9,11}$

Conventional radiation treatment involves whole-breast tangential irradiation over 5 weeks, with a subsequent boost to the tumor bed ${ }^{12}$ where indicated due to tumor and patient characteristics. Hypofractionation delivers fewer fractions with a higher daily radiation dose over a shorter period (usually 3-4 weeks) with similar efficacy $^{13,14}$ and, equivalent toxicity. ${ }^{15,16}$ In Australia, hypofractionated regimens of whole breast radiation therapy have been variably administered in the adjuvant setting in early-stage, node-negative breast cancer. ${ }^{17}$ The possible benefits and drawbacks of hypofractionated regimens in TNBC are unknown.
The present quality assurance activity reviewed patients with TNBC undergoing radiation therapy as a component of their treatment. The aims were two-fold: to determine whether treatment regimens (radiation technique, fractionation protocols, type of surgery) were associated with survival outcomes in TNBC patients and secondly, whether patient characteristics (age, laterality, nodal status) were prognostic variables in these patients.

\section{Materials and Methods}

This study was reviewed by the North Coast of New South Wales Human Research Ethics Committee (reference: QA220) and was considered to be a quality improvement project not requiring full ethical review.

A retrospective review of 2200 breast cancer patients on our electronic medical record (Mosaiq, Elekta, Crawley, United Kingdom) was undertaken; patients with TNBC treated with radiotherapy between 2006 and 2016 at the Mid-North Coast Cancer Institute and Northern New South Wales Cancer Institute were identified and their records collated. TNBC was defined by a lack of expression (or minimal expression) of estrogen receptor (ER) and progesterone receptor $(\mathrm{PR})$ as well as an absence of human epidermal growth factor receptor 2 (HER2) overexpression. ${ }^{5}$ The review identified 214 patients who had all completed surgery, chemotherapy and radiation therapy and were staged M0. Staging followed the American Joint Committee on Cancer (AJCC) Cancer Staging System, version 7. TNBC patients were treated with anthracycline and taxane-based chemotherapy regimens as the standard of care (available at www.eviq.org.au).

Disease-free survival (DFS) and overall survival (OS) were determined according to nodal status, radiotherapy technique, fractionation protocol and type of surgery. Disease-free survival was defined as the time from diagnosis to first relapse (months); OS was defined as the time from diagnosis to death from any cause (months). Regarding radiotherapy technique, conventional radiotherapy (ie, 3D conformal radiation and tangential radiation) was compared to intensity modulated radiotherapy (IMRT, which included forward planned and inverse planned IMRT). For fractionation, conventionally fractionated delivery) was compared with hypofractionated delivery. Conventional fractionation delivered 2.0 Gray (Gy) per dose in 25 fractions (50Gy total), hypofractionation 2.67 Gy per dose in 15 fractions (40.05 Gy total radiation dose). Partial breast boost (generally $10 \mathrm{~Gy}$ ) was delivered in selected cases. Finally, the effects of mastectomy or breast-conserving surgery on DFS 
and OS were evaluated. Information on subclassification of TNBC via genetic mutational analysis was not available for this QA project.

\section{Statistical Analysis}

Only deidentified patient data was subjected to statistical analysis. The clinical characteristics of the patient groups were compared using Student's $t$-test (two-tailed) for normally distributed data. Proportions were compared using Fisher's exact test (two-tailed). Corrections for multiple comparisons employed Sidak's method. Overall survival and DFS times were analyzed using the Kaplan-Meier method; the Log rank test was used to detect significant differences in survival distribution. The mean survival time was estimated as the area under the survival curve in the interval 0 to $t_{\max }$. As survival curves did not fall below 0.5, median times could not be computed. Multivariate Cox proportional hazard regression modelling was used to assess the significance of factors entered into the model. Statistical evaluations were undertaken using MedCalc v 16.8 (MedCalc Software bvba, Ostend,

Table I Clinical Characteristics of Patients with Triple Negative Breast Cancer Treated with Radiation Therapy

\begin{tabular}{|l|l|l|}
\hline Characteristics & $\mathbf{n}$ & $\%$ \\
\hline Number of patients & 214 & 100 \\
\hline Age at diagnosis (year) & & \\
Median (range) & $60.6(31-90)$ & \\
$<50$ & 42 & 19.6 \\
$\geq 50$ & 172 & 80.4 \\
\hline Laterality & & \\
Left side & 100 & 46.7 \\
Right side & 114 & 53.3 \\
\hline T-stage & & \\
TI & 111 & 51.9 \\
T2 & 84 & 39.2 \\
T3 & 13 & 6.1 \\
T4 & 6 & 2.8 \\
\hline Nodal status & & \\
No & & 62.1 \\
NI & 133 & 22.0 \\
N2 & 47 & 9.3 \\
N3 & 20 & 5.1 \\
\hline Surgery & 11 & 78.5 \\
Conserved & 168 & 21.5 \\
Mastectomy & 46 & \\
\hline
\end{tabular}

Note: ${ }^{2}$ Three patients were nodal status NX (regional lymph nodes could not be assessed (previously removed)).
Belgium); a probability $p<0.05$ (two-tailed) was considered statistically significant.

\section{Results}

\section{Demographic and Clinical Characteristics of the Study Population}

The demographic and clinical characteristics of 214 consecutive TNBC patients undergoing radiation therapy at our center are summarized in Table 1. At diagnosis, $19.6 \%$ were $<50$ years old; the majority presented with right-sided cancers (53.3\%). Most patients were T-stage T1 (tumor size $\leq 20 \mathrm{~mm} ; 51.9 \%$ ), followed by T2 (tumor size $20-50 \mathrm{~mm}$; $39.2 \%$ ) and T3 (tumor size $>50 \mathrm{~mm} ; 6.1 \%$ ). The majority were lymph node negative (N0; 62.1\%), followed by N1 $(22.0 \%)$ and $\mathrm{N} 2(9.3 \%)$. Less than half the patients (46.3\%) were treated with IMRT; two-thirds of the patients received hypofractionated doses (66.5\%). Mastectomy was less common $(21.5 \%)$ than breast conservation surgery $(78.5 \%)$.

\section{Univariate Analysis}

For the whole group, mean DFS was 106.4 (SD 48.7) months; OS 109.4 (SD 52.1) months. Chemotherapy (neoadjuvant, adjuvant) was not a significant factor for DFS ( $p=0.244)$ nor for OS $(p=0.962)$. The effect of tumor size on survival was examined in the patient cohort (Table 2 and Figure 1). Patients with T2 were significantly younger than

Table 2 Effect of Tumor Size on Disease-Free Survival and Overall Survival in Patients with Triple Negative Breast Cancer

\begin{tabular}{|c|c|c|c|c|}
\hline Tumor Size & $\begin{array}{l}\text { TI } \\
(n=\mid I I)\end{array}$ & $\begin{array}{l}\text { T2 } \\
(n=84)\end{array}$ & $\begin{array}{l}T 3, T 4 \\
(n=19)\end{array}$ & $P$ value \\
\hline $\begin{array}{l}\text { Age at diagnosis (year; } \\
\text { mean }\{S D\} \text { ) }\end{array}$ & $\begin{array}{l}67.6 \\
(10.7)\end{array}$ & $\begin{array}{l}63.2 \\
(12.7) \\
v \mathrm{TI} \\
p=0.010\end{array}$ & $\begin{array}{l}64.5 \\
(14.0)\end{array}$ & 0.038 \\
\hline $\begin{array}{l}\text { Radiation technique (n) } \\
\text { IMRT } \\
\text { 3DCRT }\end{array}$ & $\begin{array}{l}53 / 111 \\
58 / 1111\end{array}$ & $\begin{array}{l}39 / 84 \\
45 / 84\end{array}$ & $\begin{array}{l}7 / 19 \\
12 / 19\end{array}$ & \\
\hline $\begin{array}{l}\text { Fractionation (n) } \\
\text { Conventional } \\
\text { Hypofractionated }\end{array}$ & $\begin{array}{l}37 / 109 \\
72 / 109 \\
p=0.000 I^{a}\end{array}$ & $\begin{array}{l}26 / 84 \\
58 / 84 \\
p=0.000 I^{a}\end{array}$ & $\begin{array}{l}7 / 19 \\
12 / 19 \\
p=0.194^{a}\end{array}$ & \\
\hline $\begin{array}{l}\text { Disease-free survival } \\
\text { (months; mean }\{\mathrm{SD}\} \text { ) }\end{array}$ & $\begin{array}{l}106.5 \\
(39.88)\end{array}$ & $\begin{array}{l}107.3 \\
(46.47)\end{array}$ & $\begin{array}{l}54.78 \\
(46.55)\end{array}$ & $<0.0001^{b}$ \\
\hline $\begin{array}{l}\text { Overall survival (months; } \\
\text { mean }\{S D\} \text { ) }\end{array}$ & $\begin{array}{l}110.2 \\
(39.88)\end{array}$ & $\begin{array}{l}108.4 \\
(58.01)\end{array}$ & $\begin{array}{l}66.60 \\
(44.68)\end{array}$ & $0.0004^{\mathrm{b}}$ \\
\hline
\end{tabular}

Notes: ${ }^{a}$ Compared to conventional fractionation; 'Logrank test.

Abbreviations: 3D CRT, 3-dimensional conformal radiotherapy; IMRT, intensity modulated radiotherapy. 

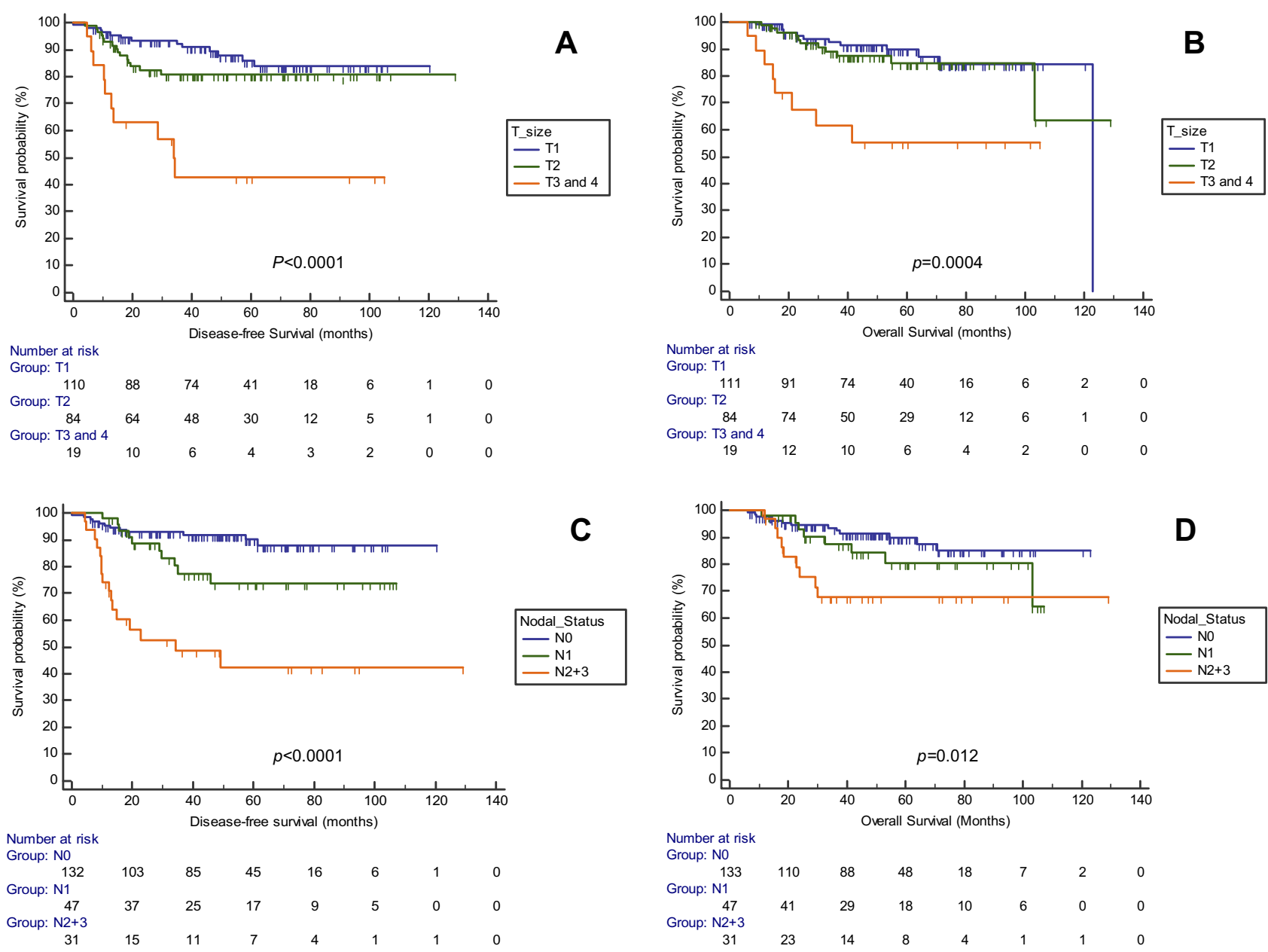

Figure I Disease-free survival $(\mathbf{A}, \mathbf{C})$ and overall survival (B, D) for triple negative breast cancer patients. Survival stratified by tumor size are compared in (A and B); survival by nodal status are compared in $(\mathbf{C}$ and $\mathbf{D})$.

T1 patients $(p=0.010)$. More patients were treated with hypofractionated protocols in the $\mathrm{T} 1$ and $\mathrm{T} 2$ groups (Both $p=0.0001)$. Survival analysis showed that both DFS $(p<0.0001)$ and OS $(p=0.0004)$ (Figure 1) differed significantly according to tumor size with shortest survival times for T3/T4 patients.

The effect of nodal status on survival was examined in the patient cohort (Table 3). Patients with nodal status N2/ $\mathrm{N} 3$ were significantly younger than N0 patients $(p=0.014)$. While more patients were treated with hypofractionated protocols in the N0 group $(p=0.0001)$, fewer patients received hypofractionated doses in the $\mathrm{N} 2 / \mathrm{N} 3$ group $(p=0.0413)$. Survival analysis showed that both DFS $(p<0.0001)$ and OS $(p=0.012)$ (Figure 1) differed significantly according to nodal status with poorer survival times for $\mathrm{N} 1$ and $\mathrm{N} 2 / \mathrm{N} 3$ patients than lymph node-negative patients.

The effect of radiation technique on survival was examined by comparing outcomes for patients receiving IMRT versus 3D CRT (Table 4). There were no differences between the groups for age at diagnosis, nor in the proportions of patients who received $50 \mathrm{~Gy}$ to the chest wall/breast, a dose to supraclavicular fossa (SCF), or a radiation boost. Survival analysis showed that radiation technique was not a significant factor for DFS $(p=0.818)$ nor for OS $(p=0.232)$ (Figure 2$)$.

The effect of fractionation protocol on survival was examined by comparing outcomes for patients receiving conventional versus hypofractionated doses (Table 5). Patients receiving conventional fractionation were significantly younger $(56.0 \mathrm{yr})$ than those receiving hypofractionation (62.7 $\mathrm{yr} ; p=0.0001)$. However, there were no significant differences between the groups for DFS $(p=0.678)$ or OS $(p=0.395)$.

The effect of type of surgery on survival was examined by comparing outcomes for patients receiving breastconserving surgery versus mastectomy (Table 6). There were no significant differences in age at diagnosis for the two surgery groups $(p=0.409)$; however, better survival 
Table 3 Effect of Nodal Status on Disease-Free Survival and Overall Survival in Patients with Triple Negative Breast Cancer

\begin{tabular}{|c|c|c|c|c|}
\hline Nodal Status ${ }^{a}$ & $\begin{array}{l}\text { No } \\
(n=133)\end{array}$ & $\begin{array}{l}\text { NI } \\
(n=47)\end{array}$ & $\begin{array}{l}N 2, N 3 \\
(n=31)\end{array}$ & $P$ value \\
\hline $\begin{array}{l}\text { Age at diagnosis (year; } \\
\text { mean }\{S D\} \text { ) }\end{array}$ & $\begin{array}{l}66.9 \\
(10.7)\end{array}$ & $\begin{array}{l}64.1 \\
(14.7)\end{array}$ & $\begin{array}{l}61.5 \\
(11.8) \\
v N 0 \\
p=0.014\end{array}$ & \\
\hline $\begin{array}{l}\text { Radiation technique (n) } \\
\text { IMRT } \\
\text { 3DCRT }\end{array}$ & $\begin{array}{l}63 / 133 \\
70 / 133)\end{array}$ & $\begin{array}{l}18 / 47 \\
29 / 47 \\
p=0.0386^{b}\end{array}$ & $\begin{array}{l}|6 / 3| \\
|5 / 3|\end{array}$ & \\
\hline $\begin{array}{l}\text { Fractionation (n) } \\
\text { Conventional } \\
\text { Hypofractionated }\end{array}$ & $\begin{array}{l}41 / 130 \\
89 / 130 \\
p=0.0001^{c}\end{array}$ & $\begin{array}{l}19 / 46 \\
27 / 46\end{array}$ & $\begin{array}{l}20 / 3 \mid \\
|| / 3 \mid \\
p=0.04 \mid 3^{c}\end{array}$ & \\
\hline $\begin{array}{l}\text { Disease-free survival } \\
\text { (months; mean }\{\mathrm{SD}\} \text { ) }\end{array}$ & $\begin{array}{l}109.3 \\
(35.57)\end{array}$ & $\begin{array}{l}86.1 \\
(39.86)\end{array}$ & $\begin{array}{l}64.82 \\
(60.80)\end{array}$ & $<0.0001^{d}$ \\
\hline $\begin{array}{l}\text { Overall survival } \\
\text { (months; mean }\{S D\} \text { ) }\end{array}$ & $\begin{array}{l}110.4 \\
(38.14)\end{array}$ & $\begin{array}{l}92.0 \\
(34.14)\end{array}$ & $\begin{array}{l}94.12 \\
(53.67)\end{array}$ & $0.012^{d}$ \\
\hline
\end{tabular}

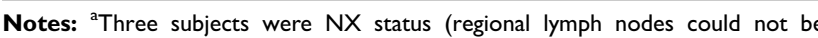
assessed [previously removed]); ${ }^{\mathrm{b} C o m p a r e d}$ to IMRT; ' $\mathrm{C}$ Compared to conventional fractionation; 'Logrank test.

Abbreviations: 3D CRT, 3-dimensional conformal radiotherapy; IMRT, intensity modulated radiotherapy.

Table 4 Effect of Radiation Technique on Disease-Free Survival and Overall Survival in Patients with Triple Negative Breast Cancer

\begin{tabular}{|l|l|l|l|}
\hline Treatment Type & $\begin{array}{l}\text { IMRT } \\
(\mathbf{n}=99)\end{array}$ & $\begin{array}{l}\text { 3D CRT } \\
(\mathbf{n}=\mathbf{I} 1 \mathbf{1 5})\end{array}$ & P value \\
\hline $\begin{array}{l}\text { Age at diagnosis (years; mean } \\
\text { \{SD\}) }\end{array}$ & $61.4(11.5)$ & $59.7(13.0)$ & 0.316 \\
\hline $\begin{array}{l}\text { Proportion receiving 50 Gy to } \\
\text { chest/breast }\end{array}$ & $33 / 99$ & $36 / 108$ & 1.00 \\
\hline $\begin{array}{l}\text { Proportion receiving dose to } \\
\text { SCF }\end{array}$ & $33 / 99$ & $37 / 110$ & 1.00 \\
\hline Proportion receiving boost & $82 / 99$ & $80 / 109$ & 0.1319 \\
\hline $\begin{array}{l}\text { Disease-free survival (months; } \\
\text { mean \{SD\}) }\end{array}$ & $83.9(35.06)$ & $105.6(46.71)$ & $0.818^{\mathrm{a}}$ \\
\hline $\begin{array}{l}\text { Overall survival (months; mean } \\
\text { \{SD\}) }\end{array}$ & $90.6(27.25)$ & $106.7(46.57)$ & $0.232^{\mathrm{a}}$ \\
\hline
\end{tabular}

Note: ${ }^{\text {aLogrank test. }}$

Abbreviations: 3D CRT, 3-dimensional conformal radiotherapy; IMRT, intensity modulated radiotherapy; SCF, Supraclavicular fossa.

outcomes were evident for both DFS and OS in the conserved group $(p<0.0001$ and $p=0.0015$ respectively $)$ (Figure 2). Reflecting these differences, T3 and T4 tumors were more common in the mastectomy group $(p=0.001$ and $p=0.020$ respectively) as were nodal status $\mathrm{N} 1, \mathrm{~N} 2$ and N3 ( $p=0.007, p=0.0005$ and $p=0.0135$ respectively). Significantly fewer mastectomy patients were categorized as T1 $(p=0.001)$ and N0 $(p<0.0001)$.

The effect of laterality on survival was examined in the patient cohort (Table 7). There were no significant differences in age at diagnosis for left versus right-sided tumors, nor in the radiation technique or fractionation protocols employed. However, irrespective of laterality, more patients were treated with hypofractionated doses than conventional protocols $(p \leq 0.0002)$. There was no difference in OS ( $p=0.383)$ or DFS $(p=0.057)$ for left versus right tumors.

\section{Multivariate Analysis}

The results of multivariate Cox proportional hazard modelling are summarized in Table 8 . When all the factors are entered into the model, only tumor size T3/T4 and nodal status $\mathrm{N} 2 / \mathrm{N} 3$ remained as significant factors for DFS ( $p=0.023$ and $p=0.0003$ respectively). Tumor size (T3/ T4) was the only significant factor for OS $(p=0.019)$; nodal status - significant on univariate analysis -radiation technique (IMRT vs 3D CRT), fractionation protocol (conventional vs hypofractionated), surgery and chemotherapy were not significant factors for OS in the multivariate model $(p>0.05$; Table 8$)$.

\section{Discussion}

In this retrospective study of 214 consecutive TNBC patients treated with radiation therapy at an Australian regional cancer center, we sought to determine whether differing treatment regimens (chemotherapy, radiation technique, fractionation protocol, type of surgery) affected survival outcomes and secondly, whether clinical characteristics were significant predictors of survival. Chemotherapy usage, radiotherapy technique and fractionation schedule, and type of surgery were not associated with DFS or OS in this patient cohort. However, nodal involvement was linked to significantly poorer DFS and OS while tumor size was the only predictor of poorer OS.

The role of breast-conserving surgery has been infrequently examined in TNBC patients. An analysis of the Surveillance, Epidemiology, and End Results (SEER) population-based database showed that breast-conserving surgery combined with radiation therapy was associated with better breast cancer-specific survival and OS compared to mastectomy. ${ }^{18}$ On multivariate analysis, advanced nodal status and tumor size were significant factors for adverse survival. A Chinese study of 308 patients, with 

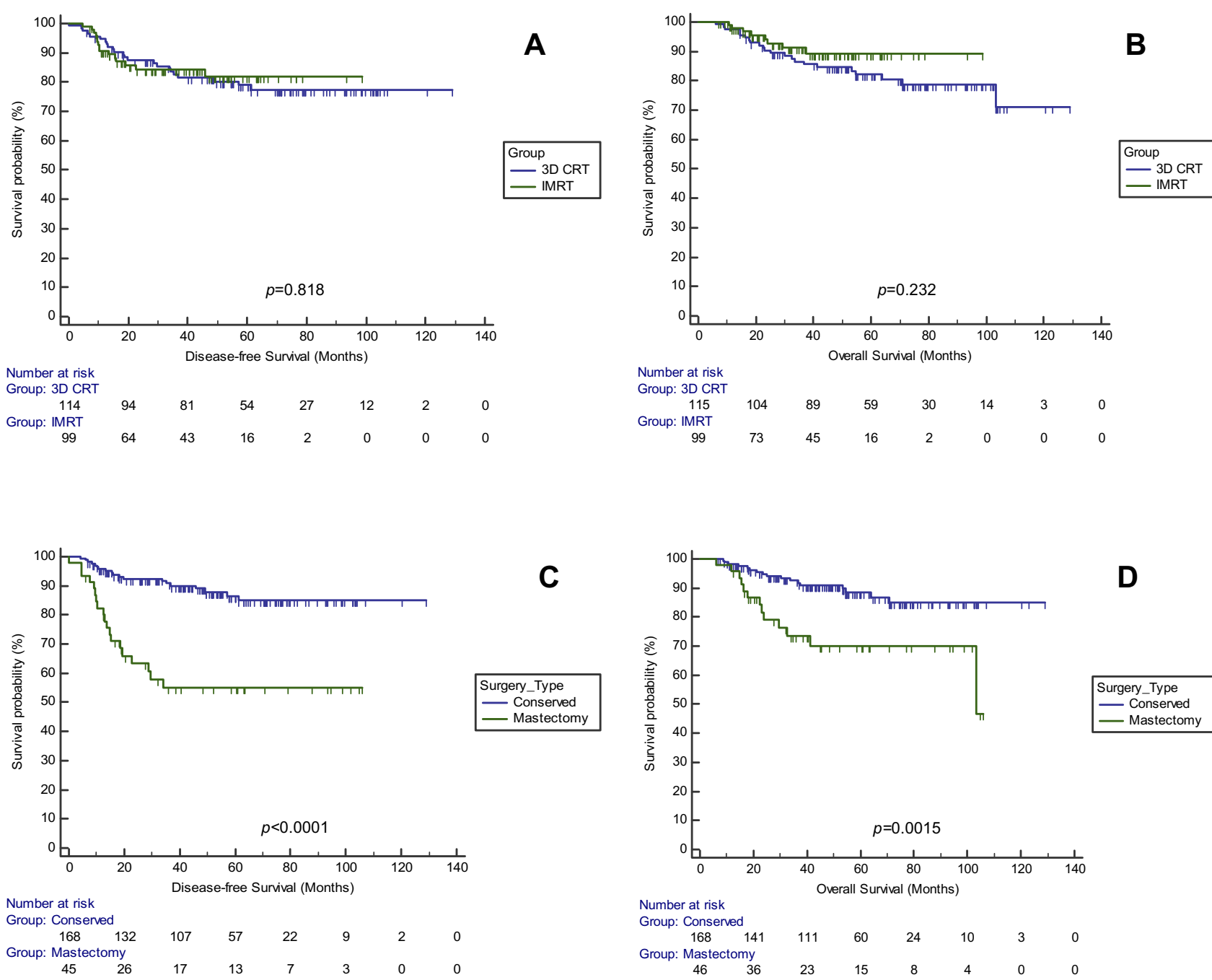

Figure 2 Disease-free survival $(\mathbf{A}, \mathbf{C})$ and overall survival (B, D) for triple negative breast cancer patients. 3D CRT and IMRT are compared in (A and B); breast-conserving surgery and mastectomy are compared in (C and $\mathbf{D})$.

Abbreviations: 3D CRT, 3-dimensional conformal radiotherapy; IMRT, intensity modulated radiotherapy.

immunohistochemically-confirmed TNBC, showed that breast-conserving surgery was not associated with increased ipsilateral tumor recurrence compared to a nonTNBC subtype cohort. ${ }^{19}$ A recent European study examined 71 TNBC patients after breast-conserving surgery and intraoperative boost radiotherapy with electrons (IOERT) followed by standard whole breast irradiation. ${ }^{20}$ After a median follow-up of 97 months (range 4-170 months), five in-breast recurrences were detected (7.0\%). Eight year actuarial rates for local control, metastases-free survival, disease-specific survival, and overall survival were 89, 75, 80 , and $69 \%$, respectively. In our patients treated with breast-conserving surgery, mean DFS was 114 months; in contrast, patients receiving mastectomy had a mean DFS of 65.2 months $(p<0.0001)$. While this difference was not significant in multivariate analysis, it is notable that the mastectomy group had more advanced disease: there were $26.1 \%$ of patients with $\mathrm{T} 3$ and above, versus $4.5 \%$ in the conserved group.

Nodal status is one of the most important clinicopathological factors with prognostic significance in breast cancer. $^{21}$ Nodal status has also been shown to be a prognostic factor for survival in TNBC in some ${ }^{22-25}$ but not all studies. ${ }^{26,27}$ In our study, lymph node negative TNBC was associated with better survival (both OS and DFS) than lymph node positive patients in univariate analysis, but the association did not apply for OS in subsequent multivariate analysis.

While there is a general trend in radiation oncology towards hypofractionation, the possible benefits and drawbacks of hypofractionated regimens in TNBC are unclear. In general, hypofractionation has been shown to deliver 
Table 5 Effect of Conventional versus Hypofractionated Radiation Doses to Chest/Breast on Disease-Free Survival and Overall Survival in Patients with Triple Negative Breast Cancer ${ }^{a}$

\begin{tabular}{|c|c|c|c|}
\hline $\begin{array}{l}\text { Chest/Breast } \\
\text { Dose (Gy) }\end{array}$ & $\begin{array}{l}\text { Conventional } \\
(n=71)\end{array}$ & $\begin{array}{l}\text { Hypofractionated } \\
(n=\mid 4 I)\end{array}$ & $P$ value \\
\hline $\begin{array}{l}\text { Age at diagnosis } \\
\text { (year; mean }\{\mathrm{SD}\} \text { ) }\end{array}$ & $56.0(10.6)$ & $62.7(12.5)$ & 0.0001 \\
\hline $\begin{array}{l}\text { Proportion receiving } \\
\text { boost }\end{array}$ & $59 / 71$ & $104 / 141$ & 0.1671 \\
\hline $\begin{array}{l}\text { Disease-free survival } \\
\text { (months; mean } \\
\{S D\} \text { ) }\end{array}$ & $107.7(45.04)$ & $84.7(38.14)$ & $0.678^{c}$ \\
\hline $\begin{array}{l}\text { Overall survival } \\
\text { (months; mean } \\
\{S D\} \text { ) }\end{array}$ & III.5 (42.97) & 88.1 (36.25) & $0.395^{c}$ \\
\hline
\end{tabular}

Notes: ${ }^{a}$ Information unavailable for 2 patients (treated offsite); ${ }^{\mathrm{b}}$ Conventiona doses totalled $50 \mathrm{~Gy}$; hypofractionated doses, $40 \mathrm{~Gy}$; 'Logrank test.

Table 6 Mastectomy versus Breast-Conserving Surgery and Disease-Free Survival and Overall Survival in Patients with Triple Negative Breast Cancer

\begin{tabular}{|c|c|c|c|}
\hline Treatment Type & $\begin{array}{l}\text { Mastectomy } \\
(n=46)\end{array}$ & $\begin{array}{l}\text { Breast } \\
\text { Conservation } \\
(n=168)\end{array}$ & $P$ value \\
\hline $\begin{array}{l}\text { Age at diagnosis (year; } \\
\text { mean }\{S D\} \text { ) }\end{array}$ & $59.3(14.5)$ & $61.0(11.7)$ & 0.409 \\
\hline $\begin{array}{l}\text { Proportion receiving } \\
\text { boost }\end{array}$ & $23 / 46$ & $139 / 168$ & $<0.0001$ \\
\hline \multicolumn{4}{|l|}{ T stage } \\
\hline $\mathrm{TI}$ & 14 (30.4\%) & 97 (57.7\%) & 0.001 \\
\hline T2 & $20(43.5 \%)$ & 64 (38.1\%) & 0.610 \\
\hline $\mathrm{T} 3$ & 8 (17.4\%) & 5 (3.0\%) & 0.001 \\
\hline $\mathrm{T} 4$ & $4(8.7 \%)$ & $2(1.5 \%)$ & 0.020 \\
\hline Nodal status ${ }^{\mathrm{a}}$ & (45) & (166) & \\
\hline No & II (24.4\%) & 123 (74.1\%) & $<0.0001$ \\
\hline NI & $17(37.8 \%)$ & 29 (I7.5\%) & 0.007 \\
\hline N2 & II (24.4\%) & 9 (5.4\%) & 0.0005 \\
\hline N3 & $6(13.3 \%)$ & $5(3.0 \%)$ & 0.0135 \\
\hline $\begin{array}{l}\text { Disease-free survival } \\
\text { (months; mean }\{\mathrm{SD}\} \text { ) }\end{array}$ & $65.2(47.88)$ & II4.2 (4I.8) & $<0.0001^{b}$ \\
\hline $\begin{array}{l}\text { Overall survival (months; } \\
\text { mean }\{S D\} \text { ) }\end{array}$ & $80.5(41.16)$ & II5.5 (40.55) & $0.0015^{b}$ \\
\hline
\end{tabular}

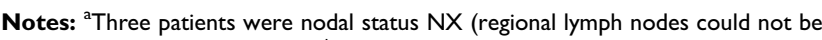
assessed (previously removed)). ${ }^{\text {b Logrank test. }}$

equivalent rates of local and locoregional control with equivalent or improved toxicity and cosmetic outcomes compared to conventional protocols. ${ }^{16,28}$ In our study, there appeared to be no worse outcomes for TNBC patients treated with the hypofractionated protocol with respect to both DFS and OS.
Table 7 Effect of Laterality on Disease-Free Survival and Overall Survival in Patients with Triple Negative Breast Cancer

\begin{tabular}{|c|c|c|c|}
\hline Laterality & $\begin{array}{l}\text { Left Side } \\
(n=100)\end{array}$ & $\begin{array}{l}\text { Right Side } \\
(n=114)\end{array}$ & $P$ value \\
\hline $\begin{array}{l}\text { Age at diagnosis (year; mean } \\
\{S D\})\end{array}$ & $65.2(12.4)$ & $65.9(11.7)$ & 0.6715 \\
\hline $\begin{array}{l}\text { Radiation technique }(\mathrm{n}) \\
\text { IMRT } \\
\text { 3DCRT }\end{array}$ & $\begin{array}{l}42 / 100 \\
58 / 100 \\
(p=0.0336)^{a}\end{array}$ & $\begin{array}{l}57 / 114 \\
57 / 114\end{array}$ & $\begin{array}{l}0.2727 \\
0.2727\end{array}$ \\
\hline $\begin{array}{l}\text { Fractionation }(n)^{b} \\
\text { Conventional } \\
\text { Hypofractionated }\end{array}$ & $\begin{array}{l}29 / 99 \\
70 / 99 \\
(p<0.0001)^{c}\end{array}$ & $\begin{array}{l}42 / 113 \\
71 / 113 \\
(p=0.0002)^{c}\end{array}$ & $\begin{array}{l}0.2457 \\
0.2457\end{array}$ \\
\hline $\begin{array}{l}\text { Disease-free survival (months; } \\
\text { mean }\{\mathrm{SD}\} \text { ) }\end{array}$ & $100.3(52.2)$ & $105.0(39.9)$ & $0.057^{d}$ \\
\hline $\begin{array}{l}\text { Overall survival (months; } \\
\text { mean }\{\mathrm{SD}\} \text { ) }\end{array}$ & $109.2(45.3)$ & $106.2(44.9)$ & $0.383^{d}$ \\
\hline
\end{tabular}

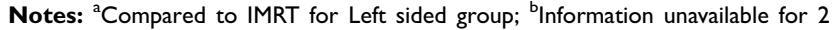
patients (treated offsite); ${ }^{\mathrm{C} C o m p a r e d}$ to conventional fractionation; ${ }^{\mathrm{d}}$ Logrank test. Abbreviations: 3D CRT, 3-dimensional conformal radiotherapy; IMRT, intensity modulated radiotherapy.

Although chemotherapy was not a focus of this study, chemotherapy usage was included as a possible factor for survival in TNBC patients. Neoadjuvant and adjuvant chemotherapy are standard systemic treatment for early TNBC, and anthracycline and taxane-based chemotherapy regimens comprise the current standard of care. ${ }^{29}$ In our study, chemotherapy (neoadjuvant, adjuvant) was not a significant factor for DFS nor for OS. However, other studies have shown that standard adjuvant chemotherapy regimens improve overall survival in TNBC patients, for example, patients with $\mathrm{T} 1 / 2$ node-positive TNBC. ${ }^{10}$

Possible limitations to this study should be considered. As this was a retrospective study, follow-up times varied widely. Nevertheless, the periods of observation extended to over 100 months, which allowed for adequate follow-up of this aggressive phenotype. Selection bias was minimized by including all TNBC patients who had completed surgery, chemotherapy and radiation therapy at our institution. However, we have not attempted to include information on type of chemotherapy such as adjuvant or neoadjuvant chemotherapy, as a survival factor.

\section{Conclusion}

We have investigated the prognostic factors for survival in a cohort of TNBC patients treated at an Australian regional cancer center. Advanced disease exhibited by positive 
Table 8 Multivariate Cox Proportional Hazard Modelling of Clinical and Treatment Factors

\begin{tabular}{|c|c|c|c|c|c|c|}
\hline \multirow[t]{2}{*}{ Variable } & \multicolumn{3}{|c|}{ Disease-Free Survival } & \multicolumn{3}{|c|}{ Overall Survival } \\
\hline & HR & $95 \% \mathrm{Cl}$ & P value ${ }^{a}$ & HR & $95 \% \mathrm{Cl}$ & P value ${ }^{a}$ \\
\hline $\begin{array}{l}\text { Radiation technique } \\
\text { 3D CRT } \\
\text { IMRT }\end{array}$ & $\begin{array}{l}1 \\
1.025\end{array}$ & 0.524 to 2.004 & 0.943 & $\begin{array}{l}1 \\
0.670\end{array}$ & 0.287 to 1.563 & 0.354 \\
\hline $\begin{array}{l}\text { Fractionation } \\
\text { Conventional } \\
\text { Hypofractionated }\end{array}$ & 1 & 0.527 to 2.257 & 0.816 & 1.298 & 0.544 to 3.096 & 0.556 \\
\hline $\begin{array}{l}\text { Surgery } \\
\text { Conserved } \\
\text { Mastectomy }\end{array}$ & $\begin{array}{l}1 \\
2.099\end{array}$ & 0.927 to 4.753 & 0.076 & $\begin{array}{l}1 \\
2.073\end{array}$ & 0.781 to 5.499 & 0.143 \\
\hline $\begin{array}{l}\text { Tumor size } \\
\text { TI } \\
\text { T2 } \\
\text { T3, T4 }\end{array}$ & $\begin{array}{l}I \\
0.984 \\
2.988\end{array}$ & $\begin{array}{l}0.440 \text { to } 2.202 \\
\text { I. } 166 \text { to } 7.655\end{array}$ & $\begin{array}{l}0.989 \\
0.023\end{array}$ & $\begin{array}{l}1 \\
1.058 \\
3.384\end{array}$ & $\begin{array}{l}0.427 \text { to } 2.622 \\
1.217 \text { to } 9.407\end{array}$ & $\begin{array}{l}0.904 \\
0.019\end{array}$ \\
\hline $\begin{array}{l}\text { Nodal status } \\
\text { No } \\
\text { NI } \\
\text { N2/N3 }\end{array}$ & $\begin{array}{l}\text { I } \\
1.558 \\
5.529\end{array}$ & $\begin{array}{l}0.601 \text { to } 4.038 \\
2.187 \text { to } 13.977\end{array}$ & $\begin{array}{l}0.362 \\
0.0003\end{array}$ & $\begin{array}{l}1 \\
0.985 \\
1.977\end{array}$ & $\begin{array}{l}0.338 \text { to } 2.870 \\
0.670 \text { to } 5.834\end{array}$ & $\begin{array}{l}0.978 \\
0.217\end{array}$ \\
\hline $\begin{array}{l}\text { Chemotherapy } \\
\text { No } \\
\text { Yes }\end{array}$ & $\begin{array}{l}1 \\
0.638\end{array}$ & 0.234 to 1.737 & 0.379 & $\begin{array}{l}1 \\
0.689\end{array}$ & 0.249 to 1.907 & 0.473 \\
\hline
\end{tabular}

Notes: ${ }^{a} P$ values were adjusted using a multivariate Cox proportional hazard regression model including all factors listed; bold type indicates significance.

Abbreviations: $\mathrm{Cl}$, confidence interval; HR, Hazard ratio; IMRT, intensity modulated radiotherapy; 3D CRT, 3-dimensional conformal radiotherapy.

nodal status and larger tumor size was associated with poorer DFS. The type of radiotherapy technique and fractionation protocol were not associated with DFS or OS.

\section{Acknowledgments}

We thank Drs Carmen Hansen, Andrew Last and Julan Amalaseelan for access to their patients' records.

\section{Disclosure}

The authors report no conflicts of interest in this work. This research did not receive any specific grant from funding agencies in the public, commercial, or not-for-profit sectors.

\section{References}

1. Australian Institute of Health and Welfare (AIHW). Australian Cancer Incidence and Mortality (ACIM) Books: All Cancers Combined. Canberra; 2017. Accessed February 12, 2017.

2. Onitilo AA, Engel JM, Greenlee RT, Mukesh BN. Breast cancer subtypes based on ER/PR and Her2 expression: comparison of clinicopathologic features and survival. Clin Med Res. 2009;7:4-13. doi: $10.3121 / \mathrm{cmr} .2009 .825$
3. Carey L, Winer E, Viale G, Cameron D, Gianni L. Triple-negative breast cancer: disease entity or title of convenience? Nat Rev Clin Oncol. 2010;7:683-692. doi:10.1038/nrclinonc.2010.154

4. Oakman C, Viale G, Di Leo A. Management of triple negative breast cancer. Breast. 2010;19:312-321. doi:10.1016/j.breast.2010.03.026

5. Pal SK, Childs BH, Pegram M. Triple-negative breast cancer: unmet medical needs. Breast Cancer Res Treat. 2011;125:627-636. doi:10.1007/s10549-010-1293-1

6. Pal SK, Mortimer J. Triple-negative breast cancer: novel therapies and new directions. Maturitas. 2009;63:269-274. doi:10.1016/j. maturitas.2009.06.010

7. Naher S, Tognela A, Moylan E, Adams DH, Kiely BE. Patterns of care and outcomes among triple negative early breast cancer patients in South Western Sydney. Intern Med J. 2018;48:567-572. doi:10.1111/imj.13628

8. Kim JE, Ahn HJ, Ahn JH, et al. Impact of triple-negative breast cancer phenotype on prognosis in patients with stage I breast cancer. $J$ Breast Cancer. 2012;15:197-202. doi:10.4048/jbc.2012.15.2.197

9. MacBride MB, Neal L, Dilaveri CA, et al. Factors associated with surgical decision making in women with early-stage breast cancer: a literature review. $J$ Womens Health (Larchmt). 2013;22:236-242. doi:10.1089/jwh.2012.3969

10. Kim HA, Seong MK, Kim EK, et al. Evaluation of the survival benefit of different chemotherapy regimens in patients with T1-2N0 triple-negative breast cancer. J Breast Cancer. 2015;18:271-278. doi:10.4048/jbc.2015.18.3.271

11. Keating NL, Landrum MB, Brooks JM, et al. Outcomes following local therapy for early-stage breast cancer in non-trial populations. Breast Cancer Res Treat. 2011;125:803-813. doi:10.1007/s10549010-0865-4 
12. EviQ Cancer Treatments Online. Breast invasive cancer adjuvant EBRT conventional whole breast. Last modified 28 April 2016. Available from: https://www.eviq.org.au/radiation-oncology/breast/1922-breastinvasive-cancer-adjuvant-ebrt-conventi. Accessed August 18, 2016.

13. EviQ Cancer Treatments Online. Breast invasive cancer adjuvant EBRT hypofractionation whole breast. Last modified 28 April 2016. Available from: https://www.eviq.org.au/radiation-oncology/breast/1923-breastinvasive-cancer-adjuvant-ebrt-hypofrac. Accessed August 18, 2016.

14. Cancer Australia. Recommendations for Use of Hypofractionated Radiotherapy for Early (Operable) Breast Cancer - A Clinical Practice Guideline. Surry Hills, NSW; 2015.

15. Shaitelman SF, Schlembach PJ, Arzu I, et al. Acute and short-term toxic effects of conventionally fractionated vs hypofractionated wholebreast irradiation: a randomized clinical trial. JAMA Oncol. 2015;1:931-941. doi:10.1001/jamaoncol.2015.2666

16. Nitsche M, Dunst J, Carl UM, Hermann RM. Emerging role of hypofractionated radiotherapy with simultaneous integrated boost in modern radiotherapy of breast cancer. Breast Care (Basel). 2015;10:320-324. doi:10.1159/000436951

17. Delaney GP, Gandhidasan S, Walton R, Terlich F, Baker D, Currow D. The pattern of use of hypofractionated radiation therapy for early-stage breast cancer in New South Wales, Australia, 2008 to 2012. Int J Radiat Oncol Biol Phys. 2016;96:266-272. doi:10.1016/j. ijrobp.2016.05.016

18. Chen Q-X, Wang -X-X, Lin P-Y, et al. The different outcomes between breast-conserving surgery and mastectomy in triple-negative breast cancer: a population-based study from the SEER 18 database. Oncotarget. 2017;8:4773-4780. doi:10.18632/oncotarget.13976

19. Wang L, Ouyang T, Wang T, et al. Safety of breast-conserving treatment for triple-negative breast cancer. Zhonghua Wai Ke $\mathrm{Za}$ Zhi. 2015;53:947-952.

20. Fastner G, Hauser-kronberger C, Moder A, et al. Survival and local control rates of triple-negative breast cancer patients treated with boost-IOERT during breast-conserving surgery. Strahlenther Onkol. 2016;192:1-7. doi:10.1007/s00066-015-0895-2
21. Wang -X-X, Jiang Y-Z, Li -J-J, Song C-G, Shao Z-M. Effect of nodal status on clinical outcomes of triple-negative breast cancer: a population-based study using the SEER 18 database. Oncotarget. 2016;7:46636-46645. doi:10.18632/oncotarget.9432

22. Steward L, Conant L, Gao F, Margenthaler JA. Predictive factors and patterns of recurrence in patients with triple negative breast cancer. Ann Surg Oncol. 2014;21:2165-2171. doi:10.1245/s10434-014-35464

23. Ovcaricek T, Frkovic SG, Matos E, Mozina B, Borstnar S. Triple negative breast cancer - prognostic factors and survival. Radiol Oncol. 2011;45:46-52. doi:10.2478/v10019-010-0054-4

24. Rakha EA, El-sayed ME, Green AR, Lee AH, Robertson JF, Ellis IO. Prognostic markers in triple-negative breast cancer. Cancer. 2007;109:25-32. doi:10.1002/cncr.22381

25. Liao GS, Chou YC, Hsu HM, Dai MS, Yu JC. The prognostic value of lymph node status among breast cancer subtypes. Am J Surg. 2015;209:717-724. doi:10.1016/j.amjsurg.2014.05.029

26. Nishimura R, Arima N. Is triple negative a prognostic factor in breast cancer? Breast Cancer. 2008;15:303-308. doi:10.1007/s12282-0080042-3

27. Shibuta K, Ueo H, Furusawa $\mathrm{H}$, et al. The relevance of intrinsic subtype to clinicopathological features and prognosis in 4266 Japanese women with breast cancer. Breast Cancer. 2011;18:292-298. doi:10.1007/s12282-010-0209-6

28. Haviland JS, Owen JR, Dewar JA, et al. The UK Standardisation of Breast Radiotherapy (START) trials of radiotherapy hypofractionation for treatment of early breast cancer: 10-year follow-up results of two randomised controlled trials. Lancet Oncol. 2013;14:1086-1094. doi:10.1016/S1470-2045(13)70386-3

29. Park JH, Ahn J-H, Kim S-B. How shall we treat early triple-negative breast cancer (TNBC): from the current standard to upcoming immuno-molecular strategies. ESMO Open. 2018;3(Suppl 1): e000357. doi:10.1136/esmoopen-2018-000357

\section{Publish your work in this journal}

Breast Cancer - Targets and Therapy is an international, peer-reviewed open access journal focusing on breast cancer research, identification of therapeutic targets and the optimal use of preventative and integrated treatment interventions to achieve improved outcomes, enhanced survival and quality of life for the cancer patient.
The manuscript management system is completely online and includes a very quick and fair peer-review system, which is all easy to use. Visit http://www.dovepress.com/testimonials.php to read real quotes from published authors. 